\title{
BUILDING FUTURE COMMUNITIES: STRENGTHENING RELATIONAL BONDS FOR A POSITIVE FUTURE
}

\author{
Ana Teixeira de Melo and Madalena Alarcão \\ University of Coimbra
}

\begin{abstract}
Communities play a special role in the development of families and their children. Community-based family support is recognized as an efficient and respectful way of helping families with complex lives. Researchers who strive to produce and share relevant knowledge with them should be concerned with the development, implementation, and assessment of these programs as well as working with the community itself to build the knowledge-guiding program development and community action. In this brief report, the authors report the process and results of 4 collaborative community reflection meetings aimed at strengthening and promoting the positive development of the families and children in the communities. We present the results of a qualitative analysis aimed at describing the communities' preferred future and identifying the processes leading to them. The authors present an emergent prototheory and discuss its implications for practice and future research. (C) 2014 Wiley Periodicals, Inc.
\end{abstract}

Collaborative and community-based interventions value knowledge and actions that are locally meaningful, congruent with the people's values, and guided by them (Lightburn \& Sessions, 2006). The synergies emerging from the interactions of local, culturally relevant, knowledge, and scientific expertise can lead to more encompassing theories and more effective practices (Horowitz, Robinson, \& Seifer, 2009).

In the following sections, we report the process and results of a series of community reflection meetings (CRMs) aimed at strengthening and promoting the positive development of the communities, their families, and children. We report what we have learned

\footnotetext{
This work was supported by a postdoctoral scholarship attributed to the first author by the Portuguese Foundation for Science and Technology (SFRH/BPD/77781/2011).

Please address correspondence to: Ana Teixeira de Melo, Apartado 1562, EC Devesas, 4400-Vila Nova de Gaia, Portugal; e-mail: anamelopsi@gmail.com
} 
from the communities about their preferred future and the core processes mediating leading to them.

\section{THE CONTEXT AND NEED FOR THIS STUDY: FOUR COMMUNITIES AND ONE FAMILY-CENTERED PROGRAM}

The context for this study is the third wave of the implementation of a community-based family assessment and intervention program designed for multichallenged families, with at-risk or maltreated children ([Blinded for review], Melo, 2011, 2012). Our most encompassing goal was to promote the well-being and positive development of the children and families. We aimed to create a favorable climate for the implementation of the program and sensitize the local community for its principles. We also aimed to increase cooperation between professionals and other people in the communities. The program should fit the communities' preferred visions of itself and its future as well as help it to realize them (Cooperrider \& Whitney, 2005; Madsen, 2009). Therefore, we aimed to explore and amplify community strengths while building knowledge to share with policy makers and the community itself to stimulate positive actions.

\section{METHOD}

\section{Participants}

Four teams of family support center professionals, working with the first author, invited two to three community partners to compose an organizing committee for a CRM, with the following objectives: (a) to identify and amplify individual and community strengths; (b) to define objectives and positive purposes for the community and its families; (c) to mobilize the community to strengthen its families and pursue the objectives defined; and (d) to define local action plans.

Each local committee selected people with relevant roles in the community to host tables in the meetings. They invited several institutions and people from the local community, defined the location, and arranged all the logistic aspects (decoration, food and beverages, and materials). We previously sent invitation letters to the participants informing them of the name, affiliation, and purposes of the researcher. The letter detailed the research objectives and methods and asked the participants for their voluntary collaboration and informed consent, which was repeated in each meeting. Although there are no institutional review boards in Portugal, the overall study was approved by the faculty's scientific board. The study was thoroughly presented to all participants, and their voluntary informed consent was again obtained in each meeting.

The total number of participants in the CRM, in the four municipalities including the team members, was 133 (mean $[M]=33$; $\min =16$; $\max =44$ ).

\section{Intervention and Data Collection Methods}

The CRM employed both intervention and data collection strategies, and the participants were inspired by collaborative approaches (Madsen, 2009). A World Café methodology (Brown, Isaacs, \& The World Café Community, 2005) was adopted. The participants were distributed around each one of five round tables. There were five rounds of debate of 20 
Table 1. Questions Used in the Five Round Table Debates

(1) What dreams and wishes should this community pursue? How do they relate to the well-being and strengthening of families and children? What will happen in 10 years when those dreams are realized?

(2) What personal strengths (qualities, talents or skills) are (or could be) placed in action that contribute to the well-being and strengthening of families with children and youth? How could those strengths be maximized, amplified or multiplied and how could they be placed at the service of other families?

(3) What strengths do families present? In what extent could the strengths of each family benefit others and how could they be shared or placed at the service of others? What has contributed to the development of such strengths and how could other families develop them?

(4) What can each person do which contributes to give the best of herself in the professional context which contributes to the well-being and strengthening of families and children? What could each one do to help other people do the same?

(5) What is the best that happens between the people that work for the well-being and strengthening of the families and children in the community? What are the characteristics of the best articulation experiences and what is the contribution of each person involved for the success of this collaboration? What conditions could facilitate the repetition, amplification and multiplication of these experiences?

minutes each. After each round, the participants moved to another table and met with different people to discuss a new set questions. Each table had a set of distinctive questions (see Table 1).

The table host welcomed and briefed the participants concerning the core ideas resulting from previous rounds and encouraged participation and the expansion and integration of ideas. The organizing committees decorated each table and had different materials available. In some sites, the decoration themes included references to the local culture. Food and beverage were available, to create an informal environment. In the end of the rounds, each table host presented the outcome of the discussion to the larger group and the researcher facilitated a final debate, posing questions for clarification, inviting new ideas, and encouraging the discussion of the implication for practice and concrete action. A very large paper panel was used to integrate and relate core ideas.

Both a strength-based philosophy (Saleebey, 2002) and a collaborative (Madsen, 2009) and appreciative stance (Cooperrider \& Whitney, 2005) inspired the dynamics of the CRM and the questions used for each round of debate (Table 1).

We collected photographic recordings of the final panels and the materials produced during the meetings, which we used to identify core themes and to write an open letter to the community describing the outcome and methodology of the CRM. The researcher sent the open letters to the core teams for review, who then forwarded them to the participants asking for their approval or suggestions of alterations. We analyzed the final versions of the four open letters to the communities.

\section{Data Analysis Methods}

We performed a qualitative analysis of the four open letters to the communities. The information contained in the four letters yielded limited data; therefore, there was no theoretical saturation. However, grounded theory methods of open coding, constant comparison, and focused coding (Charmaz, 2006) were used, as possible, to explore the data. We performed and adapted a simple form of axial coding to develop subcategories of a category and establish a link between them (Charmaz, 2006). The data were broken into small codes, which were then progressively elevated as categories or integrated as properties of core categories and their relationships explored. 


\section{RESULTS}

We report the participants' perspectives about their preferred positive future and the ingredients and processes leading to it. There may be some variation in the degree of fit of the global results of each individual letter. Nevertheless, there are many recurring themes. Three general categories serve to organize the community's views: (a) preferred outcomes for the future, (b) core processes (ingredients, practices, and experiences), and (c) strategies. We next present an integrated narrative description of the views of the communities.

\section{The Present and the Future of the Communities}

Most communities experienced some degree of challenge in looking into the future and dreaming, realizing that present problems may hinder their efforts to project an alternative, more positive future. Some communities considered they should dream with love. These dreams include ideas about a preferred internal organization, emerging from strong relational bonds, as both a product and a producer of the community, in a recurrent fashion. The community of the future should focus on itself, preserving and valuing the relationships that give rise to it. It should be strongly bonded, and individuals should participate by giving something of themselves to the community, co-constructing it with others.

Preferred values for the future include friendship and love, happiness, fraternity, social justice, liberty, equality, participation, and availability of resources. The preferred communities of the future show practices of mobility and active citizenship, preservation of the community's culture, and education through example. They are characterized by equal access to opportunities and resources and by practices of sharing, respect, social protection, and integration solidarity. Its citizens practice responsibility and have time to dedicate themselves to what is important. There are also practices for the transmission and education of values and affect, for education by example, and the promotion of well-being and health, including attention to seniors.

The participants considered the physical spaces should be high quality, functional, and well-cared-for. Relational spaces should provide its members with positive experiences, such as happiness, hope, freedom, full parental responsibility, valuing, positive occupation, and comfort.

\section{Core General Processes and Strategies Leading to Positive Preferred Future}

All communities identified strong relational bonds as the core ingredient for their positive preferred future. Love appeared as a core process for the following reasons: (a) it contributes to a better projection of the future ("we need to dream loving"); (b) it is a binding or aggregating force that compels action, calls for coordination, and leads people to act [positively] with others; and it helps each person to give their best and unites people in common dreams.

Additional core processes include keeping a focus on the (preferred) future, and enhancing the individual, the family, and the community strengths. Communities should resonate the strengths in each context and between them to amplify them and deliberately educate its members for strength development, citizenship, and the ability to choose. They should also remember the strengths of their ancestors. 
All communities highlighted Informal strategies as preferred means to strengthen relational bonds: (a) informal meetings at the community level; (b) informal community spaces and resources for informal meetings; (c) moments and spaces for shared reflection; (d) individual time to think alone; (e) shared moments of reflection and debate; (f) relationship enhancement activities; and $(\mathrm{g})$ strength development activities.

\section{Specific Individual Processes, Ingredients, and Strategies at the Individual Level}

Positive future communities depend on positive, self-oriented individual strengths as well as on relationship-oriented individual strengths. They affect the future through effective practices that benefit others, and through joint and coordinated actions.

\section{Specific Family Processes, Ingredients, and Strategies at the Family Level}

Families are the core foundations for positive future communities and family strengths are core ingredients, which include affective practices: (a) positive affective bonds (e.g., providing positive affect, love, and unconditional support; (b) being happy together and sharing positive experiences (e.g., sharing positive moments; experiencing peacefulness; expressing positive humour); (c) cognitive practices such as positive cognitive bonds (e.g., understanding; tolerance; appreciating individual and collective strengths) and a shared positive outlook toward the future; and (d) behavioural practices such as positive communication practices (e.g., dialoguing, listening) and regulation practices (e.g., experiencing cohesion, union, and sharing; following rules; respecting the other; balancing time for the family and for work). In the boundary domain, strengths relate to positive bonds with the milieu. In the resilience domain, they include the ability to overcome difficulties and solve problems. Investing in parenting and combating "love disorders" (e.g., selfishness; relational distress; low family support; parental fear; lack of time for parenting and family relations; family instability and isolation) are crucial.

Specific strategies include increasing the exchange of competencies among parents, activating the circulation of strengths in family relationships, and educating for strength development. Professionals providing formal support should be humble and motivated. They should listen to and dialogue with all family members, with a positive, respectful approach while acknowledging the family's identity and fostering internal reflexivity. They must establish close, appreciative, co-constructed, collaborative connection, and work in informal spaces. There should be a flexible network of professionals and institutions.

\section{Specific Professional and Work Context-Related Processes, Ingredients, and Strategies}

At work, each individual must cultivate a positive stance toward others-an overall positive attitude toward and in face of difficulties. The work environment and relationships must be nourished, for example, through informal strategies (e.g., shared leisure moments).

Professionals working with families must cultivate positive attitudes toward the family (e.g., accepting diversity and difference). Actions should focus on contextual conditions facilitating professional processes (e.g., coordinating professionals' strengths; increasing motivation) and family friendly services (approaching and engaging with the family in its natural contexts). 


\section{Specific Institutional and Interprofessional Processes, Ingredients, and Strategies}

At the level of the community institutions, core processes pertain to the relationships between professionals (e.g., developing a common language; showing availability and attention; articulating with the network of professionals) and organizational conditions (e.g., flexible timetable with the families' time; flexible limits between institutions).

\section{Processes at the Level of the Community as a Whole and Sustaining the Preferred Community}

Processes at the level of the community affect all other processes. Building an appreciative community is central for a positive future, such as the synchronization between individual strengths and their combination and the synchronization of individuals through their strengths. Communities must keep a focus on families, promoting informal events to facilitate the development of positive support networks. Legislative initiatives must be informed by the community.

Preferred communities need to be sustained through positive conjoint actions, cultivating talents, and educating through affection, and through positive examples, values, and citizenship. Communities must promote critical thinking and its members' ability to think together.

\section{DISCUSSION}

The communities participating in this study were able to design an image of their preferred future and define ways to pursue it. A strongly bonded community emerged, simultaneously, as a core process and a preferred outcome. Supporting families and children may be about creating "environments that shape the course of human development" (Bronfenbrenner, 2005) and the strong relational bonds that "makes human beings human" (Bronfenbrenner, 2005, p. xxvii). All communities identified some core processes to build, strengthen, and sustain such strong relational bonds. They highlighted simple and informal strategies.

\section{CONGLUSION}

The results invite politicians and practitioners to revise their priorities and dominant practices, calling for a "back to the basics" approach: the most important vehicles of human change are to care for and through relationships. The potential value of informality highlights the need to improve relationships not only within and between families, but also between families and professionals and between different professionals in the community.

As some communities pointed out, at the core of their existence there must be love, different forms of love, as a guiding, binding, and propulsion force leading the communities toward their preferred future.

\section{REFERENCES}

Bronfenbrenner, U. (2005). Making human beings human: An introduction. In U. Bronfenbrenner (Ed.), Making human beings human. Bioecological perspectives on human development (pp. xxvii-xxix). Thousand Oaks, CA: Sage. 
Brown, J., Isaacs, D., \& The World Café Community (2005). The world café. Shaping our futures through conversations that matter. San Francisco: Berret-Koehler Publishers, Inc.

Charmaz, K. (2006). Constructing grounded theory. A practical guide through qualitative analysis. London: Sage.

Cooperrider, D. L., \& Whitney, D. (2005). Appreciative inquiry. A positive revolution in change. San Francisco: Berrett-Koehler Publishers, Inc.

Horowitz, C. R., Robinson, M., \& Seifer, S. (2009). Community-based participatory research from the margin to the mainstream: Are researchers prepared? Circulation, 119, 2633-2642. doi:10.1161/CIRCULATIONAHA.107.729863

Lightburn, A., \& Sessions, P. (Eds.) (2006). Handbook of community-based clinical practice. New York: Oxford University Press.

Madsen, W. C. (2009). Collaborative helping maps: A tool to guide thinking and action in familycentered services. Family Process, 50, 529-543. doi:10.1111/j.1545-5300.2011.01369.x

Melo, A. T., \& Alarcão, M. (2011). Integrated family assessment and intervention model: A collaborative approach to support multi-challenged families. Contemporary Family Therapy, 33, 400-416. doi:10.1007/s10591-011-9168-0

Melo, A. T., \& Alarcão, M. (2012). Implementation of a community-based family-centered program in Portugal: A multiple case study evaluation. Journal of Community Psychology, 40(6), 665680. doi: $10.1002 /$ jcop. 20524

Saleebey, D. (2002). Introduction: Power in the people. In D. Saleebey (Ed.) The strengths perspective in social work practice ( $3^{\text {rd }}$ ed., pp. 1-22). Boston: Allyn \& Bacon. 
Copyright of Journal of Community Psychology is the property of John Wiley \& Sons, Inc. and its content may not be copied or emailed to multiple sites or posted to a listserv without the copyright holder's express written permission. However, users may print, download, or email articles for individual use. 